\title{
Retailing 4.0: The New Era of E-commerce in Fast Moving Consumer Goods*
}

\author{
Daniele Fornari ${ }^{* *}$, Sebastiano Grandi ${ }^{* * *}$, Edoardo Fornari ${ }^{* * * *}$
}

\begin{abstract}
The arrival of the online channel has initiated a new cycle in competitiveness among retailers characterized by shoppers' increasing nomadism around physical and digital touch points. The present work adopts a supply-side analytical approach to highlight drivers and perspectives of e-commerce development within the grocery sector. Research results emphasize that: (i) online-native retailers hold a wellestablished position of leadership worldwide and thus fundamentally influence egrocery dynamics as a whole; (ii) the e-commerce channel is characterized by profit margins that are significantly lower than store-based channel ones. This represents the main limitation to online grocery sales growth, above all for offline-native retailers who maintain core business in their bricks \& mortar stores.
\end{abstract}

Keywords: E-Grocery; Online/Offline-Native Retailers; E-Commerce P\&L; Omni-channel Retailing; Global Markets

\section{Introduction}

The world of retailing has significantly changed in the last two decades due to the disruptive development of the online channel (Christensen \& Raynor, 2003), so that in 2017 e-sales reached the overall value of 2,290 USD billion worldwide, the highest ever ${ }^{1}$. More generally, the arise of the new "digital era" stimulated scholars to rethink market economy paradigms, considering new business models based on technological breakthrough innovations and on a new "digital culture" which is gradually permeating companies (Lambin, 2014). This constitutes a fundamental challenge in that it creates opportunities for opening new research perspectives on global competition issue, assuming a market-driven orientation aiming at in-depth studying the emerging need, for global corporations, to better understand the phenomenon of increasing customer empowerment (Brondoni \& Pironti, 2015).

Starting from these assumptions, within the retail management sphere several studies have explored the topic of increasing competition between channels; more

\footnotetext{
* The Authors: D. Fornari $\S \S 1,2$, S. Grandi $\S \S 3,4$, E. Fornari $\S \S 5,6$.

** Full Professor of Marketing, Università Cattolica, Piacenza (daniele.fornari@unicatt.it)

*** Associate Professor of Marketing, Università Cattolica, Piacenza (sebastiano.grandi@ unicatt.it)

***** Associate Professor of Marketing, Università Cattolica, Piacenza (edoardo.fornari@unicatt.it)

${ }^{1}$ Source: eMarketer
}

Edited by: University of Milano - Bicocca

ISSN: 1593-0319

Fornari, D., Grandi, S. \& Fornari, E. (2018). Retailing 4.0: The New Era of E-commerce in Fast Moving Consumer Goods, Symphonya. Emerging Issues in Management (symphonya.unimib.it), 2, 77-90.

http://dx.doi.org/10.4468/2018.2.07fornari.grandi.fornari 
particularly, scholars are deepening the sales trade-off from store-based channels to e-commerce. This sales transfer is actually determining a new phase in the Retail Revolution, in which intra- and intertype competition between modern and traditional store formats, previously defined by the expression "store wars" (Wrigley, 1994), is joined by, and in some cases substituted by, competition between physical stores and digital platforms. This phenomenon is certainly favoured by the growing tendency of shoppers to adopt "multiple channel shopping" behaviour (Gijsbrechts et al., 2008; Chatterjee, 2010; Sonnech \& Ott, 2010). It is a new purchasing model based on constant interaction with multiple touch points offered by retailers, which are used in either a complementary and/or alternative way according to specific needs of the moment, determining ever increasing and more significant migration between the channels (Yang \& Peterson, 2004; Chintagunta et al., 2012; Trevinal \& Stenger, 2014). In this respect, many drivers are favouring a growing use by shoppers of the new (online) channel together with/in place of more traditional (offline) ones: (i) functionality and convenience linked to $\mathrm{H} 24,365$ day-a-year accessibility from ecommerce websites everywhere (Campo \& Breugelmans, 2015); (ii) the possibility to achieve significant savings thanks to an effective instantaneous comparison of prices and intense sales promotions (Lynch \& Ariely, 2000); (iii) meeting variety seeking needs thanks to a range/depth of assortment which is potentially infinite (Weitz, 2010; Terblanche, 2018); (iv) the availability of a vast amount of updated information which guarantees maximum offer transparency and fully aware purchasing choices (Alba et al., 1997). This is particularly important for food products, whose full traceability is considered crucial by consumers (Reitano et al., 2016); (v) the chance to personalize contents of retailing services, passing from a "browsing" type model of purchasing (selecting the best alternative within a limited range preselected by the retailer), to a more advanced "searching" type (identifying the best choice in absolute terms) (Levene, 2011).

In the light of these important elements, which are destined to favour a structural increase in online purchases, the majority of studies on Retailing 4.0 have concentrated on the analysis of demand-side (pull) dimensions. Scientific production relative to supply-side dimensions, or rather to the influence that push drivers can have, for better or for worse, on evolutionary dynamics of the e-commerce channel, has been less plentiful.

Starting from these assumptions, the present work adopts the latter perspective of analysis, aiming at deepening the topic of the competitive role assumed by the new online channel from the retailer's point of view and referring specifically to the Fast Moving Consumer Goods (FMCG) sector. In particular, there are two main objectives of the paper herein. The first consists in the investigation of positioning of different grocery e-tailing models, distinguishing between online-native and offlinenative. The second is that of assessing the degree of retailers' economic sheet sustainability in the online channel compared to more traditional store-based ones.

The work is structured in five Sections. The first presents preliminary evidence on the most recent dynamics of e-commerce in the FMCG sector worldwide. The second discusses a review of existing literature and proposes research questions. The third sheds light on different grocery e-tailing clusters and their positioning. The fourth shows the economic unsustainability of online channel and, lastly, the fifth suggests managerial implications and concludes. 


\section{Preliminary evidence on e-grocery retailing}

Most recent statistics show that e-commerce global sales recorded an annual average growth rate of $+22.5 \%$ from 2013 to 2017 , reaching a market share equal to $10.1 \%$ of global retail sales (Table 1). The economic significance of the online channel would thus appear to be rather substantial but destined to further consolidate over the next few years, considering that double-digit growth is typical of phenomena which are still in the initial phase of their life-cycle. Besides, e-commerce market share is seen to differ greatly both among geographical areas and industries; there is, in fact, a wide gap between more developed countries like China (23\%) and the UK $(19 \%)$ on one hand in comparison with "backward" ones like France $(7 \%)$ and Italy $(6 \%)$ on the other. In the same way, online sales shares are much higher in music and video $(60 \%)$, books $(40 \%)$ and toys $(30 \%)$, while it is much more limited in the automobile market (2\%), among others. In the FMCG (grocery ${ }^{2}$ ) sector it is estimated that global online sales were equal to about 152 billion dollars in 2017. This is a significant and fast-growing value $(+21 \%$ only last year) in absolute terms, but representing only $6.6 \%$ of the whole e-commerce turnover and $1.2 \%$ of global FMCG retail sales worldwide. This indicates on one hand that in the case of groceries ecommerce currently still represents a marginal channel compared to store-based ones, but on the other that consistent growth rates may be still forecast for coming years. In fact, only considering the last year, e-commerce generated $36 \%$ of the whole global FMCG sales growth, thus representing the main developing area both for retailers and manufacturers ${ }^{3}$.

Table 1: Global e-commerce turnover and market share 2013-2017

\begin{tabular}{|c|c|c|c|c|}
\hline Years & $\begin{array}{c}\text { Global } \\
\text { e-commerce turnover } \\
\text { (USD billion) }\end{array}$ & $\begin{array}{c}\text { Share of e-commerce } \\
\text { on global retail sales } \\
(\%)\end{array}$ & $\begin{array}{c}\text { Global FMCG } \\
\text { e-commerce turnover } \\
\text { (USD billion) }\end{array}$ & $\begin{array}{c}\text { Share of e-commerce } \\
\text { on global FMCG } \\
\text { retail sales (\%) }\end{array}$ \\
\hline 2013 & 1,077 & $5.1 \%$ & 61 & $0.7 \%$ \\
\hline 2014 & 1,336 & $6.3 \%$ & 85 & $0.8 \%$ \\
\hline 2015 & 1,548 & $7.4 \%$ & 106 & $1.0 \%$ \\
\hline 2016 & 1,859 & $8.7 \%$ & 126 & $1.1 \%$ \\
\hline 2017 & 2,290 & $10.1 \%$ & 152 & $1.2 \%$ \\
\hline
\end{tabular}

Source: Authors' elaboration on eMarketer and Planet Retail data

The fact that grocery purchases currently made online are still limited does not mean that there is not a considerable demand base for this channel. In fact, it is estimated that web channel penetration for FMCG purchasing in 2017 was equal to $45 \%$ in Germany, $42 \%$ in the UK, $35 \%$ in Spain and 32\% in Italy ${ }^{4}$. Moreover, about a third of European shoppers have got used to searching for pre-purchasing information on the Internet; this means that the digital channel is slowly becoming part of consumers shopping behaviour. In the light of this evidence, the research hypothesis on which the present work is based is that the reduced market share

\footnotetext{
${ }^{2}$ By FMCG (grocery) sector is meant aggregate sales in food and beverage departments together with (non-food) home care, health \& beauty and pet care departments.

${ }^{3}$ Source: Kantar Worldpanel, “The future of e-commerce in FMCG”, Issue 4, November 2017.

${ }^{4}$ Source: IRI, “European Shopper Survey”, 2017.
} 
hitherto reached by e-commerce in the FMCG sector can probably not be exclusively attributed to demand-side limitations, but rather to supply-side deficit.

\section{Literature review and research questions}

Studies that have so far investigated the topic of e-commerce taking a supply-side perspective can be classified into two main branches.

The first one has dealt with deepening opportunities linked to the development of the online channel for retailers, identifying four main areas of opportunity. The first such area is that of breaking the bonds linked to trading areas' presence since digital stores allow for a potential extension of the business area to countries all over the world; this determines not only a high potential of sales, but also a series of benefits for the retail brand, which may lead to a chain of positive halo-effects both in terms of brand awareness and brand image (Kwon \& Lennon, 2009). The second area of opportunity lies in the possibility of intercepting the needs of many targets/profiles of shoppers, thanks to an extremely wide and deep assortment which allows exploitation of benefits of hyper-segmentation both at category and brand level (Weitz, 2010). The third area of opportunity lies in the reduction of execution problems typical to retail strategies performed in a store-based context; in fact, the website eliminates situations of variability and lack of homogeneity of company offer by means of standardization of service contents (assortments, pricing and customer service among others) dictated principally by the lack of the "human" component in the delivery of the same service (Dickson, 2000). Finally, the fourth area of opportunity is represented by real-time and low-cost access to a wealth of information on real purchasing behaviour of e-shoppers; in particular, by means of cookies, e-tailers can monitor a singles user's navigation during different phases of the buying process, following times and ways of interaction with website contents; it follows that there is a chance to develop particularly effective Customer Relationship Management (CRM) policies (Srinivasan \& Moorman, 2005).

The second branch of studies is the one which has deepened the topic of multichannel retailing, or rather simultaneous management by the same retailer of online and offline sales channels. It is a strategy that has been defined as: "the design, deployment and evaluation of channels to enhance customer value through effective acquisition, retention, and development" (Neslin et al., 2006). This represents an extraordinary opportunity for diversifying risks for the company and for strengthening trust with consumers.

However, the multiplication of channels must be evaluated very carefully in that it passes through the difficult operation of channel addition. More recent studies on this topic have considered not only the most widespread type defined by the expression "adding web to store" relating to the development of the new online channel by retailers who are already operating in store-based channels (Deleersnyder et al., 2002; Biyalogorsky \& Naik, 2003; Lee \& Grewal, 2004; Weltevreden, 2007), but also the opposite one, which has recently been consolidating, defined as "adding store to web" and based on the opening or acquisition of "physical" stores by players who were previously only active on the Internet (Avery et al., 2012; Bell et al., 2015; Pauwels \& Neslin, 2015; Fornari et al., 2016).

Apart from the form of new channel addition, these studies have also shown that simultaneous management of "physical" and "digital" channels may determine 
negative effects (cannibalism) and positive ones (synergy) on reciprocal sales performance.

Cases of cannibalism tend to appear most significantly in the initial phases of multichannelling. This is because very often shoppers who are not wholly satisfied with the service they received in the previously-existing channel, simply migrate to the new one with the expectation of obtaining greater satisfaction, generating a zero-sum effect on company turnover (Falk et al., 2007; Ansari et al., 2008; Ofek et al., 2011; Laudon \& Traver, 2017).

On the other hand situations of synergy tend to emerge more significantly in the medium-long term, when multi-channelled retailers are able to start a virtuous cycle which foresees the habit of shoppers to equally purchase both online and offline with high customer satisfaction that is similar in both channels (Kwon \& Lennon, 2009). This mechanism produces an increase in total company turnover thanks to the fact that the same shopper can interact with the retailer through multiple touch points to which he may accede at a variety of times and situations which are complementary rather that alternatives to each other (Wallace et al., 2004; Kim \& Park, 2005).

The chance to make the synergy effect prevail over the cannibalization one depends principally on the ability of retailers to manage different channels in a coordinated and integrated way. This brings about a gradual organizational and cultural evolution to omni-channel retailing, defined as: "the synergetic management of the numerous available channels and customer touchpoints, in such a way that the customer experience across channels and the performance over channels is optimized" (Verhoef et al., 2015).

It is a concept considered as an improvement of multi-channelling; in fact if the latter presupposes a net division among various channels managed as separate and autonomous SBUs, omni-channel management foresees, on the contrary, that the shopper may move freely among the same channels, also within the same shopping experience, at any time an in any place. This means that all the services offered by an omni-channel retailer are accessible to the same extent and with the same methods (that is with the same retail-mix) in all company channels, according to the principles of seamless retailing (Beck \& Rygl, 2015).

The present work is placed within the auspices of this second branch of studies, with the aim of deepening on one hand the positioning of different e-tailing models and on the other the impact of the online channel on retailers' performance, referring in both cases to the specific FMCG sector.

In particular, concerning grocery e-commerce models, to the best of our knowledge studies hitherto carried out have mainly been limited to describing different profiles of multichannel retailers, without highlighting their competitive position and development dynamics. Starting from this consideration, the present work aims to bridge this gap, responding to the following research question:

\section{RQ1: What is the contribution of online-native and offline-native retailers to turnover and growth of e-commerce in the FMCG sector?}

With reference to the impact of the digital channel on retailers' performance the majority of studies hitherto carried out have concentrated on effects relating to total sales. On the contrary, less attention has been paid to effects on levels of retailers' profitability. In this regard, the present work intends to contribute with incremental analysis through the following research question: 
RQ2: What is the average level of profitability of the e-commerce channel compared to store-based ones in the FMCG sector?

\section{Offline- and online-native retailers' positioning in e-grocery}

In order to provide an answer to RQ1, Planet Retail source data regarding the top 50 global retailers in terms of e-grocery sales in 2017 were processed. The representative value of this sample is guaranteed by the fact that their aggregate market share out of global online grocery sales was of $95.7 \%$ in 2017 ; moreover, this figure grew significantly from $92.4 \%$ in 2013 . These retailers were classified into two different clusters. The first one was that of offline-native (36 out of 50); these are players who had started their business in store-based channels and for whom the majority of grocery sales in 2017 was still carried out in such a way. On the contrary, the second cluster was that of online-native players (14 out of 50) who had started their business via the digital channel and who kept their core business in the same sphere, having realized the majority of their grocery sales for 2017 via web (Table 2).

Analysis of 2013-2017 accumulated turnover data for retailers belonging to both clusters highlights three particularly significant aspects. The first is that the strategic group of online-natives holds a solid leading position in comparison to offlinenatives. Although the number of these operators is significantly lower, their sales weight for 2017 was equal to $71.9 \%$ over the whole, which is a big increase on the $59.0 \%$ for 2013.

The second aspect is represented by the fact that compound annual growth rate (CAGR) of online grocery sales in the last five years was led mainly by the remarkable performance of online-native players, while offline-native ones recorded an average sales growth trend which was decidedly more modest (equal to about a third.) Finally, the third aspect is that FMCG share out of the total retailers' turnover realized through the e-commerce channel has a majority (equal to an average of $68.8 \%$ ) for the offline-native cluster, while it is decidedly in the minority (15.7\%) for the online-native one.

Table 2: Offline versus online-native retailers' parameters

\begin{tabular}{|l|c|c|c|}
\hline \multicolumn{1}{|c|}{ Parameters } & $\begin{array}{c}\text { Offline-native } \\
\text { retailers }\end{array}$ & $\begin{array}{c}\text { Online-native } \\
\text { retailers }\end{array}$ & $\begin{array}{c}\text { Top-50 grocery } \\
\text { e-tailers overall }\end{array}$ \\
\hline$\%$ on total FMCG e-sales 2013 & 41.0 & 59.0 & 100.0 \\
\hline$\%$ on total FMCG e-sales 2017 & 28.1 & 71.9 & 100.0 \\
\hline CAGR FMCG e-sales 2013-2017 & $+14.7 \%$ & $+41.8 \%$ & $+30.7 \%$ \\
\hline$\%$ FMCG on total banner sales 2017 & 68.8 & 15.7 & 55.8 \\
\hline
\end{tabular}

Source: Authors' elaboration on Planet Retail data

This evidence brings to light that the current main success driver for grocery ecommerce is represented not so much by specific sales skills for these types of goods, but rather by the ability to develop particular know-how pertinent to the new online channel effectively and efficiently, independently of the type of product/service offered. This is confirmed by the interesting case of Wal-Mart, the global leader in store-based channels, who are investing over the medium-long period in a gradual 
but deep repositioning aimed at transforming the company into a digital platform to all intents and purposes ${ }^{5}$. Despite being aware of the difficulties with an evolved presence within the online channel for a concern which is accustomed to leadership in offline channels, Wal-Mart are progressively modifying their strategic priorities, reducing focus on new store openings in favour of growing investments in technological infrastructure and digital skills. In particular, by means of the creation of @ WalmartLabs division, the company are busy acquiring advanced know-how on the big data management front and are trying out new instruments and technological applications in order to speed up and streamline the process of online service provision.

For offline-native retailers like Wal-Mart the need to quickly bridge the competitive gap with online-native players moreover derives from the fact that the latter are characterized by a disruptive company culture; they are constantly innovative and ever ready to adapt by means of their innate agility, with a tendency to embrace high risks and readiness to invest significantly and constantly in R\&D. Such marked gifts of speed and adaptability are leading companies like Alibaba and Amazon to try out new forms of business, favouring gradual widening of their operating areas as well as means and opportunities to interact with consumers. They are real "digital ecosystems" which carry out many more activities besides retailing (Rieple \& Pisano, 2015). These new hybrids, also defined by the expression "blended", have three main aims:

- increase company size by exploiting the potential of each activity in order to widen their business and start making new earnings;

- increase the quantity and quality of available data in order to improve awareness of shoppers' needs and therefore make their offer more personalized;

- multiply opportunities for interaction with individuals by activating new physical and digital touch points so as to enter more into people's daily habits and thus increase switching costs for shoppers who leave these players to go to the competition.

Among the most significant activities are data collection on shoppers' profile and their purchasing behaviour on one hand, and management of third-party (3P) marketplace platforms on the other. Concerning data, these are ever-increasingly representing the real digital ecosystems' driver; the ability to elaborate them and subsequently to cash in on their value through re-selling, constitutes the basis of the system since it becomes the main source of company revenues.

For these players continuous information collection about customers represents the principal source of product/service design innovation and, consequently, for gaining differential competitive advantage (Brondoni, 2015).

As regards the marketplace, this is an extremely promising area in that it allows companies to play the simple role of virtual intermediary who matches supply and demand. These portals act as digital hubs, which are able to offer high visibility to independent sellers who can exploit the potential of these web "shop windows" to promote their offer efficiently and well beyond the geographical limits which they could otherwise explore by themselves. The third party provides its own know-how in website management and in product presentation, besides guaranteeing wide coverage and high visibility towards e-shoppers. Within the grocery sector this is a

\footnotetext{
${ }^{5}$ In 2017 Wal-Mart CEO Doug McMillon, declared: “This company, over time, is going to look like more of an e-commerce company. We're not a retailer competing in Silicon Valley. We're building an Internet technology company inside the world's largest retailer" (Source: Planet Retail).
} 
way to host a multitude of niche agri-food sellers in order to offer wider assortment and better-quality products than those of e-tailers who prefer to sell directly to end consumers. Besides, this business model also tends to favour improvements of partnerships with manufacturers, because they are given greater autonomy in manoeuvring all retail-mix online levers as well as in the management of developing relationships with e-shoppers.

The benefits obtained through data selling and marketplace allow the online-native blended companies to avail themselves of significant amounts of cash flow which are generally reinvested in strengthening other ecosystem activities and mainly in technological innovation. This leads to activating a virtuous circle, which allows these operators to become the most reliable brands in the online channel and gain further advantage over more traditional offline-native players.

Within the sphere of the online-native retailer cluster there are also mono-channel operators, who currently prefer to limit their activity to exclusively web retail. These are increasingly significant players like Ocado (Uk) and Freshdirect (Usa) who have achieved an important market share thanks to dual specialization; goods (only grocery products) and channel (online-pure.) In a prospect of growing concentration of market shares, it is nevertheless to be expected that particularly positive sales performances during recent years make these companies more attractive for takeovers by both online- and offline-native retailers, in order to strengthen their competitive position in the web channel.

\section{E-grocery economic unsustainability}

Also in the FMCG sector, the e-commerce channel features sales values that are growing constantly and significantly. However, in order to assess the effective contribution of this channel to retailers' performance, it is necessary to deepen the analysis also considering costs linked to online sales. To do this, in order to answer RQ2, Planet Retail data relating to a number of balance sheet items of grocery retailers were elaborated; average values of various $P \& L$ items were re-classified into two clusters, e-commerce channel and store-based channels' ones (Table 3).

Table 3: E-commerce versus store-based grocery retailers $P \& L(\%, 2017)$

\begin{tabular}{|l|c|c|}
\hline \multicolumn{1}{|c|}{ P\&L items } & E-commerce channel & Store-based channels \\
\hline Revenues & 100.0 & 100.0 \\
\hline COGS (Cost Of Goods Sold) & 83.3 & 79.4 \\
\hline Gross margin & 16.7 & 20.6 \\
\hline Operating expenses & 16.3 & 17.8 \\
\hline- Store rental & - & 3.5 \\
\hline- Personnel & 3.4 & 8.3 \\
\hline- Fulfilment & 7.4 & 3.0 \\
\hline- Marketing & 2.5 & 1.5 \\
\hline- Technology & 3.0 & 1.5 \\
\hline Operating income & 0.4 & 2.8 \\
\hline
\end{tabular}

Source: Authors' elaboration from Planet Retail data 
Analysis of data obtained by means of re-classification shows that average operating income of e-commerce is practically null $(0.4 \%)$ and, however, significantly worse than that of more traditional store-based channels $(2.8 \%)$. This means that online grocery sales do not currently allow for satisfactory profitability levels in that it is characterized on one hand by a very low gross margin (given by the difference between revenues and COGS), and on the other by a heavy structure of costs despite the elimination of the item "store rental" and the consequent reduction in remuneration of employees.

Concerning the question of margins, this depends essentially on two factors. The first one is e-tailers' intense aggressiveness in sales prices. This regards policy dictated both by the presence of a very high number of competitors and by a distinctive choice of positioning towards consumers. Unlike what happens in "physical" stores, where overlapping of players is limited from the spatial point of view, so much so that competitive price monitoring usually includes only retailers present in the trading area in question, on the Internet price comparison on same products is potentially unlimited (Ancarani e Shankar, 2004). This determines a significant widening in the range of direct or indirect competitors who may constitute an object of comparison by e-shoppers with the involvement of both general and specialized store formats, just as of local, national and international players. Furthermore, the chance to widen the borders of price comparisons is favoured by the spreading of so-called "price-matching providers", or rather search engines, which, by means of a sophisticated system of automatized aggregation, allow shoppers to compare sales prices of a specific item/service proposed by all websites that are offering it in their assortment in real time. It is therefore a question of a competitive scenario that compels retailers to continually strive to align prices with the lowest level, above all within the digital ecosystem sphere in order never to end up out of the market and in order not to feel the effects of the natural selection process typical of the fierce price war which always occurs during the initial phases of a new channel's lifecycle. This happens because of a massive use of price promotions but also of ever-increasingly frequent repositioning of baseline prices, so that the final combined effect of these factors constitutes, in many sectors, an acceleration of the physiological phenomena of price erosion. Besides, the need to increase customer base and to augment average purchasing frequency passes through the proposal of particularly effective elements of distinction in comparison with store-based channels; in this sense price competitiveness represents the principal lever of attraction in order to stimulate inter-channel mobility; this presupposes systematic monitoring of physical stores' price levels besides that of online competitors. This strategic positioning choice also appears a virtually compulsory path to follow in the present stage in which e-commerce is still associated with such a reliability gap that there are no other retail marketing levers through which this channel may credibly establish its superiority in comparison with others.

The second factor that penalizes online margins is a mix of purchases in which product/brands with high margins represent limited shares on total sales. The difficulty of websites in stimulating impulse buying and, more generally, all "touch and feel" goods (such as fresh foods,) usually characterized by higher than average margins, determines a composition of the digital bill that is decidedly influenced by high programming categories, which, however, usually return lower than average returns. Besides, online sales tend to be concentrated on A-brands, which are usually characterized by more contained unit margins, while followers and lesser brands, with higher margins, often turn out to be below fair share. This is the consequence 
of the fact that reduced reliability often associated with e-tailers is transformed into the search by e-shoppers for other reassuring elements, which in many cases are found in the most famous and credible manufacturing brands. It follows that online brand loyalty levels are higher than those found in physical channels (Arce-Urriza \& Cebollada, 2012; Dawes \& Nenycz-Thiel, 2014).

The main problem of economic sustainability of the e-commerce channel is, however, represented by the fact that the gross margin gap compared with storebased channels is only partially compensated for by greater efficiency in operations. There are, in fact, a number of cost items that show a very high incidence on grocery e-tailers' revenues. This is a particular question of costs relating to logistic activities and infrastructures, marketing and technology. This means that, even though ecommerce is able to depend on a significant saving area (almost 8.5 percentage points) relating to store rentals and to personnel, on the whole its aggregate operating costs are lower than those of store-based channels by only 1.5 percentage points; this does not compensate for its initial gap in gross margins.

Fulfilment costs refer on one hand to storage of assortments and, therefore, to purchase/rent management of warehouses and, on the other, to delivery activities. In both cases it is a question of costs linked to supply chain management activities, which lead not only to significant investments in infrastructures, but also advanced know-how in assortment planning, stock and refill management, delivery times and scheduling. The greater variety of choice offered to consumers in comparison with stores, in fact, means an increase in storage costs caused by the rise in the number of active SKUs and a consequent reduction in average rotation indexes. Meanwhile, home delivery of goods ordered online is an extremely complex activity, above all from the organizational point of view, so much so that in the majority of cases etailers opt for outsourcing to external carriers who are specialized in this type of business. The main problem with this shipping management activity is that consumers' orders are usually small and their fast processing leads to the need to plan trips which cannot be previously scheduled; this happens continually, so that they cannot always guarantee a full load and they risk heading for remote/isolated destinations. It is a question of very different conditions compared to the typical ones of store-based channels, where logistic cycles are only internal and concern the transport of products from central warehouses to single stores. This means that delivery flows are based upon planned trips that are always fully loaded and with concentrated destinations; in this scenario home delivery is independently managed by consumers on the basis of so-called "prosumerism"; this allows offline retailers to save on related costs. On the contrary, in the case of the online channel the delivery phase, also defined as the last-mile one, not only leads to a much higher outlay, but also significantly contributes to defining levels of e-customer satisfaction. Therefore, there is a need to sustain significant strategic investments, which are not easily reducible, in such a sphere in order to consolidate the retail brand's reputation and thus to improve website productivity.

Considering marketing and technology costs, their significant impact on the echannel balance sheet derives on one hand from website management activities and on the other from those of e-shopping behaviour database management. The former deals with sustaining important investments in terms of IT but also acquiring advanced know-how in the creation and following maintenance of the company website pages. It is a question of developing design creativity, of organizing different sections' architecture, of creating contents, of manoeuvring and updating single retail-mix levers (pricing, assortment, merchandise and so on) in real time, adapting 
them to the specific requirements of the digital context. Similarly, in the case of database management activities it is a question of activating very advanced and complex data collection and analysis capabilities. The possibility of profiling website visitors and, consequently, of adapting tailor-made company proposals actually passes through the acquisition of tools and skills necessary for the analysis of socalled Big Data. It follows that the covering of these technological and marketing costs may come about only in the medium-long term when the effects of respective activities have produced results which allow companies to reach proportionate sales levels, besides generating stable improvements in the retailer's own brand image.

\section{Emerging issues and managerial implications}

Research results obtained with reference to the two RQs proposed in the previous Sections allow us to formulate a number of concluding insights and to identify various important managerial implications, which represents significant emerging issues both for scholars and practitioners.

The first issue concerns the fact that the e-grocery sector is highly concentrated on supply-side at a global level. This means that e-commerce development dynamics are at present strongly dependent on investment strategies of a limited number of big international players who, however, are increasingly consolidating their own leading positions. It follows that retailers intending to strengthen their online presence will have to undergo consolidation operations of scale or rather, through M\&A activities aimed at reaching a critical mass, which can compete with these big players. This is necessary above all because of present $\mathrm{P} \& \mathrm{~L}$ structure, which appears particularly negative considering the heavy fixed costs of the online channel, particularly in the current phase, which, for many retailers, is still in its initial stage with high start-up investments, which necessitate achieving adequate revenues to cover them. The only feasible alternative strategic option for lesser grocery e-tailers could be to turn to a 3P marketplace platform managed by global leaders.

A second insight is that the competitive position of offline-native grocery retailers is marginal compared to that of online-natives. This largely depends on the fact that the approach hitherto adopted by more traditional players in the FMCG sector towards the e-commerce channel has been of a tactical nature. The principles of prudence and gradual growth have nearly always guided sustained investments. The process of channel addition has in fact been perceived by many retailers as compulsory but not desired; in many cases they thought they could manage it by minimizing efforts and resources, an approach defined as "good enough." There has followed a model of offer which is often loss making and consequently a reduced level of e-shoppers' satisfaction, triggering a sort of vicious circle which has ended up further discouraging investments in offer improvement; assortment is often more limited and more superficial compared to those of physical stores; prices are not particularly competitive and are increased by delivery costs; in many trading areas ecommerce services are no more accessible and even where coverage is guaranteed delivery is not effected quickly or punctually; the graphical interface of websites is often little cared for and does not work well in a context like that of grocery shopping, in which many items are bought at a single purchase, so that expectations of convenience and speed of navigation are particularly high. It follows that the chance for offline-native retailers to bridge the competitive gap hitherto accumulated towards online-natives necessarily passes through a change of approach towards a 
more strategic one. This leads to a radical change in the mix of company investments destined to channels. They need to significantly re-dimension resources for stores networks switching them towards the strengthening of e-commerce, both in terms of infrastructure and skills.

A third insight is the observation that online-native retailers, and in particular those characterized by the previously defined "blended" model, do not have their core business in the FMCG sector. This means that grocery e-commerce is currently managed as an area of offer integration to consolidate consumers' trust, but which is certainly not profitable. It follows that these retailers tend to adopt an opportunistic and often particularly aggressive sales policy in this sphere, determining intense competitiveness with other online retailers and other channels. This approach is made possible because these players can compensate for negative performances in egrocery with more positive ones realized through other product/service sales managed in their own digital ecosystem.

Finally, a fourth insight is linked to conditions of e-commerce profitability, which are, in the FMCG sector, currently worse than store-based channel ones. This fact risks being the principal structural limitation to online sales growth. Offline-native multichannel retailers tend to maintain a cautious attitude towards investments in the new online channel. A strong promotion of the latter would, in fact, risk generating sales cannibalization to the detriment of physical stores, ending up penalizing companies' balance sheets. The possibilities of modifying this scenario depend on two givens; the first is improving capacity to sustain online sales for high margin categories/brands and the second is contracting fulfilment costs through the implementation of new delivery methods. In the first case it is interesting to note that major online-native global retailers are developing $\mathrm{O} 2 \mathrm{O}$ (from Online-To-Offline) solutions, which are also aimed at acquiring greater know-how in the sale of "senseand-feel" products like fresh foods and in impulse buying management. In the second case, "click and collect" model, that is, offline picking up of an order placed online by shoppers themselves, seems particularly effective; moreover, tests of unattended home delivery, where online purchases are delivered to special lockers, to car boots or directly to home pantries, allow retailers to manage deliveries more efficiently.

In conclusion, the present work's results seem to suggest the fundamental emerging issue that online grocery sales' growth perspectives depend mainly on supply-side factors, that is, retailers' ability and will to invest in incremental improvement of their e-commerce offer, adopting an omni-channel strategy aimed at exploiting elements of integration rather than cannibalization with their store-based channels.

\section{Bibliography}

Alba J., Lynch J., Weitz B., Janiszewski C., Lutz R., Sawyer A., Woods S. (1997). Interactive Home Shopping: Consumer, Retailer and Manufacturer Incentives to Participate in Electronic Marketplaces, Journal of Marketing, (61), 38-53. https://doi.org/10.2307/1251788

Ancarani F., Shankar V. (2004). Price Levels a Price Dispersion Within and Across Multiple Retailer Types: Further Evidence and Extension, Journal of the Academy of Marketing Science, (32/2), 176187. https://doi.org/10.1177/0092070303261464

Ansari A., Mela C.F., Neslin S.A. (2008). Customer Channel Migration, Journal of Marketing Research, (45/1), 60-75.

https://doi.org/10.1509/jmkr.45.1.60 
Arce-Urriza M., Javier Cebollada J. (2012). Private Labels and National Brands Across Online and Offline Channels, Management Decision, (50/10), 1772-1789.

https://doi.org/10.1108/00251741211279594

Avery J., Steenburgh T., Deighton J., Caravella M. (2012). Adding Bricks to Clicks: Predicting the Patterns of Cross-Channel Elasticities over Time, Journal of Marketing, (76/3), 96-111. https://doi.org/10.1509/jm.09.0081

Beck N., Rygl D. (2015). Categorization of Multiple Channel Retailing in Multi-, Cross-, and OmniChannel Retailing for Retailers and Retailing, Journal of Retailing and Consumer Services, (27), 170-178.

https://doi.org/10.1016/j.jretconser.2015.08.001

Bell D.R., Gallino S., Moreno A. (2015). Showrooms and Information Provision in Omni-Channel Retail, Production and Operations Management, (24/3), 360-362.

https://doi.org/10.1111/poms.12258_2

Biyalogorsky E., Naik P. (2003). Clicks and Mortar: the Effect of Online Activities on Offline Sales, Marketing Letters, (14), 21-32.

https://doi.org/10.1023/A:1022854017292

Brondoni S.M. (2015). Product Design Management and Global Competition, Symphonya. Emerging Issues in Management (symphonya.unimib.it), (2), 13-24.

http://dx.doi.org/10.4468/2015.2.02brondoni

Brondoni S.M., Pironti M. (2015) Ouverture de 'Design Management, Product Engineering and Global Competition', Symphonya. Emerging Issues in Management (symphonya.unimib.it), (2), 112.

http://dx.doi.org/10.4468/2015.2.01ouverture

Campo K., Breugelmans E. (2015). Buying Groceries in Brick and Click Stores: Category Allocation Decisions and the Moderating Effect of Online Buying Experience, Journal of Interactive Marketing, (31), 63-78.

https://doi.org/10.1016/j.intmar.2015.04.001

Chatterjee P. (2010). Causes and Consequences of "Order Online Pick up in-Store" Shopping Behavior, International Review of Retail, Distribution and Consumer Research, (20/4), 431-448. https://doi.org/10.1080/09593969.2010.504009

Chintagunta P.K., Chu J., Cebollada J. (2012). Quantifying Transaction Costs in Online/Offline Grocery Channel Choice, Marketing Science, (31/1), 96-114.

https://doi.org/10.1287/mksc. 1110.0678

Christensen C.M., Raynor M.E. (2003). The Innovator's Solution, Harvard Business Press, Boston.

Dawes J., Nenycz-Thiel M. (2014). Comparing Retailer Purchase Patterns and Brand Metrics for InStore And Online Grocery Purchasing, Journal of Marketing Management, (30/3-4), 364-382. https://doi.org/10.1080/0267257X.2013.813576

Deleersnyder B., Geyskens I., Gielens K., Dekimpe M.G. (2002). How Cannibalistic Is the Internet Channel? A Study of the Newspaper Industry in the United Kingdom and the Netherlands, International Journal of Research in Marketing, (19/4), 337-348. https://doi.org/10.1016/S0167-8116(02)00099-X

Dickson P.R. (2000). Understanding the Trade Winds: The Global Evolution of Production, Consumption and the Internet, Journal of Consumer Research, (27/1), 115-122. https://doi.org/10.1086/314313

Falk T., Schepers J., Hammerschmidt M., Bauer H. (2007). Identifying Cross-Channel Dissynergies for Multichannel Service Providers, Journal of Service Research, (10/2), 143-160. https://doi.org/10.1177/1094670507306683

Fornari E., Fornari D., Grandi S., Menegatti M., Hofacker C.F. (2016). Adding Store to Web: Migration and Synergy Effects in Multi-Channel Retailing, International Journal of Retail \& Distribution Management, (44/6), 658-674. https://doi.org/10.1108/IJRDM-07-2015-0103

Gijsbrechts E., Campo K., Nisol P. (2008). Beyond Promotion-Based Store Switching: Antecedents and Patterns of Systematic Multiple-Store Shopping, International Journal of Research in Marketing, (25), 5-21. https://doi.org/10.1016/j.ijresmar.2007.07.001

Kim J., Park J. (2005). A Consumer Shopping Channel Extension Model: Attitude Shift toward the Online Store, Journal of Fashion Marketing and Management, (9/1), 106-121. https://doi.org/10.1108/13612020510586433

Kwon W-S., Lennon S.J. (2009). Reciprocal Effects between Multichannel Retailers' Offline and Online Brand Images, Journal of Retailing, (85/3), 376-390. 
http://dx.doi.org/10.1016/j.jretai.2009.05.011

Lambin, J. J. (2014). Rethinking the Market Economy. Symphonya. Emerging Issues in Management (symphonya.unimib.it), (2), 4-15.

http://dx.doi.org/10.4468/2014.2.02lambin

Laudon K.C., Traver C.G. (2017). E-commerce 2016. Business, Technology, Society, 12th Edition, Pearson Education, Upper Saddle River.

Lee R.P., Grewal R. (2004). Strategic Responses to New Technologies and Their Impact on Firm Performance, Journal Of Marketing, (68/4), 157-171.

https://doi.org/10.1509/jmkg.68.4.157.42730

Levene M. (2011). An Introduction to Search Engines and Web Navigation, John Wiley and Sons, Hoboken.

Lynch J., Ariely D. (2000). Wine Online: Search Costs Affect Competition on Price, Quality and Distribution, Marketing Science, (19), 83-104.

https://doi.org/10.1287/mksc.19.1.83.15183

Neslin S., Grewal D., Leghorn R., Shankar V., Teerling M., Thomas J., Verhoef P. (2006). Challenges and Opportunities in Multichannel Customer Management, Journal of Service Research, (9/2), 95112. https://doi.org/10.1177/1094670506293559

Ofek E., Katona Z., Sarvary M. (2011). Bricks and Clicks: The Impact of Product Returns on the Strategies of Multichannel Retailers, Marketing Science, (30/1), 42-60. https://doi.org/10.1287/mksc. 1100.0588

Pauwels K., Neslin S.A. (2015). Building with Bricks and Mortar: The Revenue Impact of Opening Physical Stores in a Multichannel Environment, Journal of Retailing, (91/2), 182-197. https://doi.org/10.1016/j.jretai.2015.02.001

Reitano A., Fazio M., Taylor D.W. (2016), Traceability of Food Products in Global Gastronomic Tourism, Symphonya, Emerging Issues in Management (symphonya.unimib.it), (2), 46-59. http://dx.doi.org/10.4468/2016.2.06reitano.fazio.taylor

Rieple A., Pisano P. (2015), Business Models in a New Digital Culture: The Open Long Tail Model. Symphonya. Emerging Issues in Management (symphonya.unimib.it), (2), 75-88 http://dx.doi.org/10.4468/2015.2.06pisano.rieple

Sonneck P., Ott C.S. (2010). Future Trends in Multi-Channel Retailing, in Krafft M., Mantrala M., eds. "Retailing in the 21st Century. Current and Future Trends" 2 nd edition, Springer-Verlag, Berlin Heidelberg, 221-238.

Srinivasan R., Moorman C. (2005). Strategic Firm Commitments and Rewards for Customer Relationship Management in Online Retailing, Journal of Marketing, (69/4), 193-200. https://doi.org/10.1509/jmkg.2005.69.4.193

Terblanche N.S. (2018). Revisiting the Supermarket In-Store Customer Shopping Experience, Journal of Retailing and Consumer Services, (40), 48-59.

https://doi.org/10.1016/j.jretconser.2017.09.004

Trevinal A.M., Stenger T. (2014). Toward a Conceptualization of the Online Shopping Experience, Journal of Retailing and Consumer Services, (21/3), 314-326. https://doi.org/10.1016/j.jretconser.2014.02.009

Verhoef P.C., Kannan P.K., Inman J.J. (2015). From Multi-Channel Retailing to Omni-Channel Retailing. Introduction to the Special Issue on Multi-Channel Retailing, Journal of Retailing, (91/2), 174-181. https://doi.org/10.1016/j.jretai.2015.02.005

Wallace D., Giese J., Johnson J. (2004). Customer Retailer Loyalty in the Context of Multiple Channel Strategies, Journal of Retailing, (80/4), 249-263. https://doi.org/10.1016/j.jretai.2004.10.002

Weitz B.A. (2010). Electronic Retailing, in Krafft M., Mantrala M., eds. "Retailing in the 21st Century. Current and Future Trends" 2nd Edition, Springer-Verlag, Berlin Heidelberg, 357-371.

Weltevreden J.W.J. (2007). Substitution or Complementarity? How the Internet Changes City Centre Shopping, Journal of Retailing and Consumer Services, (14/3), 192-207.

https://doi.org/10.1016/j.jretconser.2006.09.001

Wrigley N. (1994). After the Store Wars: Towards a New Era of Competition in UK Food Retailing?, Journal of Retailing and Consumer Services, (1/1), 5-20. https://doi.org/10.1016/0969-6989(94)90024-8

Yang Z., Peterson R.T. (2004). Customer Perceived Value, Satisfaction, and Loyalty. The Role of Switching Costs, Psychology \& Marketing, (21/10), 799-822. https://doi.org/10.1002/mar.20030 